'Fundação Oswaldo Cruz, Programa de Pós-Graduação em História das Ciências e da Saúde, Brasil maio@fiocruz.br

II Fundação Oswaldo Cruz, Programa de Pós-Graduação em História das Ciências e da Saúde, Brasil

lopes_47@hotmail.com

Marcos Chor Maio' Thiago da Costa Lopes"

\title{
"FOR THE ESTABLISHMENT OF THE SOCIAL DISCIPLINES AS SCIENCES": DONALD PIERSON E AS CIÊNCIAS SOCIAIS NO RIO DE JANEIRO (1942-1949)
}

Dentre os sociólogos estrangeiros que participaram do processo de institucionalização das ciências cociais no Brasil durante os anos I930 e I940, destacou-se o norte-americano Donald Pierson, cujo amplo raio de ação foi fundamental na construção de um espaço acadêmico e de uma identidade profissional para os cientistas sociais no país. Professor da Escola Livre de Sociologia e Política (ELSP), o sociólogo atuou como pesquisador, coordenador de projetos em parceria com instituições norte-americanas, tradutor, editor e organizador de coleções na área de ciências sociais, empenhando-se tanto em associar ensino e pesquisa quanto em divulgar uma sociologia fundada na investigação empírica. Formado na tradição de pesquisas que emergiu na Universidade de Chicago nos anos I920 e I930 em torno de Robert Park e Ernest Burgess, Pierson buscava distinguir a sociologia de outros saberes e práticas relativos à vida social, enfatizando o status científico da disciplina e seu parentesco com as ciências naturais. "For the establishment of the social disciplines as sciences" foi o lema utilizado pelo sociólogo na tentativa de atribuir um sentido ao conjunto de suas atividades no Brasil, conferindo-lhes ares de missão. ${ }^{\mathrm{I}}$

O impacto da perspectiva de Pierson acerca do fazer sociológico e do papel do sociólogo como cientista-pesquisador não se restringiu ao círculo imediato dos alunos que passaram pela ELSP, a exemplo de Oracy Nogueira, Florestan Fernandes, Darcy Ribeiro e Virgínia Leone Bicudo. ${ }^{2}$ A correspondência mantida com cientistas sociais de diferentes regiões do país revela o esforço 
em divulgar suas ideias. Pierson buscou estabelecer uma extensa rede de interessados por meio da qual suas concepções sobre a "Ciência da Sociologia" pudessem circular.

Abordamos neste artigo a recepção, no Rio de Janeiro, da sociologia de Chicago representada por Donald Pierson a partir da experiência intelectual e profissional de Luiz de Aguiar Costa Pinto e Alberto Guerreiro Ramos. Pertencentes à primeira turma de cientistas sociais da Faculdade Nacional de Filosofia da Universidade do Brasil, eles seguiram caminhos distintos. Enquanto Costa Pinto se manteve ligado à universidade, buscando construir uma carreira acadêmica, Guerreiro Ramos enveredou pela burocracia do Estado, atuando em órgãos de planejamento. Ainda que situados em diferentes contextos institucionais, ambos se apropriaram das ideias de Pierson acerca do trabalho sociológico em um esforço de legitimar espaços próprios de atuação no campo intelectual. Conforme argumentavam, em uma sociedade em mudança, a função do sociólogo não podia mais ser preenchida por autodidatas que se dedicavam, senão ocasionalmente, a desenvolver interpretações sobre o país sem o devido conhecimento positivo da vida social.

O estudo da recepção de autores e obras tem sido uma forma de chamar a atenção para os significados e funções variáveis que estes assumem ao circularem para além dos contextos originais de sua produção, sendo lidos sob o prisma de diferentes agendas, interesses, perspectivas e tradições nacionais (Bourdieu, 2002; Grynszpan, 2012). Em se tratando da história das ciências sociais no Brasil, abordagens em termos de recepção têm buscado analisar as lógicas de leitura e reelaboração que presidiram o contato de cientistas sociais brasileiros com diferentes tradições sociológicas no esforço de compreensão das peculiaridades cognitivas da sociologia que se constituiu no país. A noção de recepção torna possível evidenciar o caráter ativo e seletivo da apropriação local de ideias e autores estrangeiros, oferendo uma visão alternativa às interpretações que associam o desenvolvimento das ciências sociais no país à transposição mecânica de modelos gestados na Europa e nos Estados Unidos (Villas Bôas, 2006a).

Para compreendermos como a sociologia de Pierson foi incorporada por Costa Pinto e Guerreiro Ramos, analisamos o posicionamento destes atores frente a questões-chave do debate sobre a institucionalização das ciências sociais nos anos I940, como a cientificidade da sociologia, as condições sociais de seu florescimento, a relação ensino-pesquisa, a atuação profissional do sociólogo e seu papel social. Partimos da hipótese de que as ideias de Pierson fundamentaram distintos projetos de constituição do campo científico da sociologia no Rio de Janeiro. Não obstante suas especificidades, Costa Pinto e Guerreiro Ramos apostaram na possibilidade de conciliação entre pesquisa e engajamento dos sociólogos, alterando uma importante premissa da sociologia 
de Pierson: o distanciamento do cientista em relação à esfera política. Eles se punham em continuidade com a tradição do pensamento brasileiro que, preocupada em compreender as especificidades da realidade social do país, buscava enfrentar os problemas que impediam sua inserção no mundo moderno.

Inicialmente, apresentamos a perspectiva de Pierson quanto à atuação do sociólogo profissional e o desenvolvimento das ciências sociais à luz de suas atividades no Brasil ao longo da década de I940. Em seguida, no intuito de avaliar o impacto de suas ideias, analisamos a experiência universitária das ciências sociais no Rio de Janeiro. Por fim, cotejamos as concepções de Pierson, Costa Pinto e Guerreiro Ramos acerca da cientificidade da sociologia e dos papéis sociais a serem desempenhados pelo sociólogo a fim de compreender as interpretações que se fizeram das concepções veiculadas pelo professor da ELSP.

\section{A SOCIOLOGIA É CIÊnCIA? A VISÃo DE DONALD PIERSON}

Após se formar na Universidade de Chicago, tendo defendido tese de doutorado sobre as relações raciais na cidade de Salvador, Donald Pierson foi contratado para lecionar na ELSP em I939, exercendo inúmeras atividades no terreno das ciências sociais, como a criação de espaços institucionais de formação acadêmica com base no ensino e na participação dos alunos em projetos coletivos de pesquisa. O trabalho de campo de Pierson (I935-I937), que se fez acompanhar da visita de seu orientador, Robert Park, em I937, contribuiu para que Salvador viesse a ser considerada, por pesquisadores estrangeiros, importante laboratório para o estudo das relações de raça e cultura (Valladares, 2010).

Na ELSP, Pierson organizou e dirigiu o Departamento de Sociologia e Antropologia Social, instituindo um seminário extracurricular de Métodos e Técnicas de Pesquisa, e criou, em I94I, junto aos antropólogos Herbert Baldus e Emílio Willems, a primeira Seção de Estudos Pós-Graduados em Ciências Sociais do país. No início dos anos I940, Pierson promoveu levantamentos referentes à alimentação e à habitação na cidade de São Paulo com o objetivo de treinar alunos no uso de instrumental de pesquisa. Em I945, tornou-se o responsável no Brasil pelo Programa do Instituto de Antropologia Social do Smithsonian Institution, conseguindo atrair recursos para projetos de pesquisa. Realizou levantamentos prévios em cidades no interior de São Paulo, Minas Gerais e Rio de Janeiro e, entre I947 e I948, sempre assistido por alunos, conduziu um estudo de comunidade em Araçariguama, cujos resultados deram origem, em I95I, à publicação de Cruz das Almas: a Brazilian village (Pierson, I987). No início dos anos I950, coordenando diferentes equipes de pesquisadores, Pierson promoveu amplo projeto de investigação em localidades distribuídas pelo Vale do São Francisco (Maio et al., 2013). 
A chegada de Pierson à ELSP em I939 significou uma reorientação do projeto original da instituição, fundada por médicos, engenheiros e intelectuais oriundos das elites políticas e econômicas de São Paulo um ano após a derrota da Revolução Constitucionalista de I932. O enfoque aplicado nas ciências sociais, ${ }^{3}$ ligado ao interesse de seus fundadores em formar uma nova classe dirigente para o país imbuída de espírito científico, cedeu espaço gradativamente a uma preocupação maior com o treinamento profissional e a produção de conhecimento referidos ao mundo acadêmico (Limongi, I989; Oliveira, I995a; Vila Nova, I998).

À época em que Pierson se formou na Universidade de Chicago, havia um esforço crescente de seus pesquisadores em delimitar as fronteiras disciplinares da sociologia, diferenciando-a de atividades de cunho reformador ou assistencial (Chapoulie, 200I). Com efeito, a tradição de investigação empírica de Chicago havia surgido no seio do movimento de reforma promovido por setores médios de extração protestante em resposta aos inúmeros problemas sociais decorrentes do boom demográfico e do acelerado crescimento urbano-industrial da cidade a partir do final do século XIX (Coulon, I995; Valladares, 2005).

A caracterização da atividade do sociólogo profissional e das normas que deveriam pautar sua conduta foi constante nos textos que Pierson produziu no Brasil nos anos 1940. Ele insiste em distinguir a sociologia de outras formas de análise e de outras práticas dedicadas à vida social, como o pensamento social, a filosofia social, a ética e o serviço social. À diferença destas áreas de conhecimento, a sociologia se empenhava na sujeição sistemática de hipóteses e teorias às descobertas decorrentes da pesquisa, à luz das quais aquelas seriam mantidas, modificadas ou refutadas. Ao pôr o sociólogo em contato com coisas, para além do debate de ideias, a pesquisa conduzia ao progressivo refinamento da teoria, ao acúmulo de proposições universalmente válidas, sendo capaz de superar velhas controvérsias filosóficas entre escolas e tradições nacionais e produzir consenso científico (Pierson, I945a).

Pierson conferiu relevo à coleta de dados em primeira mão e à imersão do pesquisador no campo, na esteira dos estudos que se desenvolveram em Chicago sob a orientação de Robert Park e Ernest Burgess (Bulmer, I984). Formado em uma tradição disciplinar que valorizava a associação estreita entre sociologia e antropologia social, Pierson mostrava preferência por um modelo investigativo de cunho etnográfico sem aderir, contudo, a uma visão ingênua de objetividade segundo a qual os fatos falariam por si mesmos. Buscando se afastar do empiricismo, o sociólogo sublinhava a importância da teoria na observação da realidade aproximando-se da tradição antropológica da pesquisa etnográfica (Cavalcanti, I999: I92). Na visão de Pierson, o "fact-finding", isto é, o acúmulo de fatos avulsos sem referência a um quadro teórico ou a hipóteses de pesquisa, constituía, tanto quanto a especulação filosófica vazia, ameaça ao desenvolvimento do conhecimento sociológico (Pierson, I945a: 60-62). 
Ele argumentava que a ciência de que era portador não constituía o desdobramento de uma escola norte-americana, mas era fruto de um empreendimento coletivo global. Além de instituir a pesquisa, os sociólogos norte-americanos haviam travado contato com a produção intelectual europeia, rompendo as fronteiras nacionais que poderiam restringir o alcance de suas teorias. Pierson afirmava que este cosmopolitismo intelectual era condição indispensável para a consolidação da sociologia enquanto ciência: "Quando o isolamento [cultural] desaparecer completamente em todos os países e for possível uma comunicação livre e desembaraçada entre todos os sociólogos do mundo, o desenvolvimento de um corpo comum de conhecimentos sociológicos será questão de tempo relativamente curto" (Pierson, I945a: 95).

Fazendo um diagnóstico da situação brasileira, Pierson observa, na correspondência com Costa Pinto, que a falta de profissionais treinados em pesquisa, capazes de trabalhar de forma conjunta e coordenada em torno de uma mesma linguagem conceitual, era, em grande parte, responsável pelo estágio pré-científico da produção intelectual local. Predominavam, no país, os "lero lero boys" 4 ou "amadores" 5 , em geral médicos, engenheiros e advogados de formação que se limitavam a compor textos a partir da combinação de pontos de vista e teorias heterogêneas e da livre manipulação de ideias sem o respaldo da empiria. Pierson afirmava que muito "ecletismo", "ginástica intelectual"6 e "brilhantismo de simples erudição" se passava por sociologia, em um expediente característico das ciências sociais em processo de institucionalização, cujos atores muitas vezes se valeram de categorias genéricas, como a de ensaísmo, para designar as atividades intelectuais das quais buscavam se diferenciar (Botelho, 2010: 48).

Tal argumentação de Pierson não era estranha a setores da intelectualidade brasileira que vinham buscando se especializar em torno da atividade científica e tachavam de antiquadas as manifestações de enciclopedismo e beletrismo associadas ao mundo dos bacharéis (Sá, 2006). O esforço de Pierson em dotar a sociologia de uma identidade própria remonta às disputas que as ciências sociais, a partir do século XIX, tiveram de travar com a literatura ao buscarem se afirmar como a fonte legítima de interpretação das modernas sociedades ocidentais (Lepenies, I996).

Em levantamento sobre a bibliografia de interesse sociológico produzida no Brasil até I940, Pierson observa que este material se encontrava disperso entre estudos de outras áreas, tais como história, geografia, economia, etnologia, e entre comentários eruditos sobre a sociedade e a cultura brasileiras (Pierson, I945b). Embora oferecesse importantes insights e hipóteses de pesquisa, principalmente em se tratando de estudos históricos, romances e crônicas de viagem, a literatura do país era constituída, em sua maioria, ou por dados descritivos reunidos de forma pouco sistemática ou por análises de cunho especulativo e normativo (Pierson, I945b). 
A despeito desta situação, Pierson demonstrava otimismo acerca do futuro da disciplina no país, ${ }^{8}$ esboçando, em sua correspondência com Costa Pinto, uma análise dos processos sociais que alavancariam seu desenvolvimento:

A situação atual no Brasil não é muito diferente da norte-americana de há tempos. [...] À medida que esta grande shift [guinada] de uma base agrícola para a industrial, bem como a atual tendência à urbanização, se forem processando, os antigos controles baseados em contatos primários enfraquecer-se-ão cada vez mais, tornando-se, assim, emancipated [emancipados] os indivíduos de modo que surgirão constantemente novos problemas sociais ao mesmo tempo em que os já existentes tornar-se-ão mais agudos. Uma vez que o homem só pensa ao enfrentar problemas, vai haver aqui mais pensamento sobre assuntos sociais. E, havendo mais preocupação, haverá, sem dúvida, mais desejo de estudar e pesquisar no nosso campo.9

Para Pierson, a tendência brasileira seguia os passos dados por esta ciência nos Estados Unidos, onde a mudança social fornecia forte impulso para a sua institucionalização. Desencadeando uma série de situações de tensão ligadas à desestruturação do mundo tradicional, o processo de mudança fomentava o interesse público pela disciplina com base na expectativa de que ela pudesse conferir inteligibilidade aos problemas sociais daí decorrentes. Pierson tinha em mente questões como "o crime, a delinquência juvenil, o divórcio, a insanidade mental, a guerra”, que fizeram parte da agenda de pesquisa dos sociólogos de Chicago (Pierson, I946a: I02).

Pierson indicava, todavia, reservas quanto à possibilidade de aplicação do conhecimento sociológico a curto e médio prazos. Sem deixar de reconhecer que o ideal de controle humano sobre a natureza fazia parte do horizonte da ciência moderna, ${ }^{\text {Io }}$ ele ponderava que somente quando o desenvolvimento das ciências sociais fosse comparável ao da atual física seria possível lidar eficazmente com os processos sociais:

O desenvolvimento das ciências sociais é [...] ainda bem modesto. É pena, pois, que os sociólogos e outros cientistas sociais estejam atualmente sob a pressão de alguns governos, aliás bem intencionados, para resolverem, desde já, seus problemas práticos. Se quisermos escapar à pecha de presunçosos e pretensiosos, e ser intelectualmente sinceros e honestos conosco mesmos, com os colegas e com os demais, devemos reconhecer isto e admitir francamente que ainda não estamos em condições de dar, de maneira certa, todos os conselhos que se desejam (Pierson, I946a: I02).

Na perspectiva de Pierson, o sociólogo devia estar comprometido, sobretudo, com o avanço do conhecimento científico. ${ }^{\text {I }}$ A subordinação da pesquisa básica a interesses extracientíficos imediatos podia, ademais, comprometer-lhe a objetividade. Era preciso controlar os vieses da pesquisa, decorrentes de sua participação em determinada cultura, sociedade, época, classe e círculo de pessoas (Pierson, I946a: 90). 
Não obstante essas advertências, Pierson tinha consciência de que a legitimação social das ciências sociais passava pela produção de conhecimento útil. Ele não perdeu de vista as demandas das classes dirigentes, inclusive de setores ligados à criação da ELSP, ao buscar fontes de financiamento para suas atividades na instituição. Desde meados dos anos I930, carecendo de recursos próprios, a ELSP desenvolveu estreitos laços de colaboração com setores da administração pública da cidade de São Paulo que viabilizaram a pesquisa, como os estudos sobre o padrão de vida dos trabalhadores paulistanos realizados por Horace Davis e Samuel Lowrie (Del Vecchio \& Diéguez, 2008). Em I94I, Pierson apresentou relatório com os resultados parciais de sua investigação sobre os tipos de habitação da cidade de São Paulo no Instituto de Organização Racional do Trabalho (IDORT), órgão fundado por membros da elite industrial modernizante de São Paulo tendo em vista o incremento da produtividade fabril e a reforma das condições de vida do operariado. ${ }^{\mathrm{I2}} \mathrm{Na}$ ocasião, o sociólogo ressaltou que, embora seu objetivo fosse o treinamento de alunos em pesquisa, os dados obtidos se prestavam ao uso tanto de cientistas quanto de assistentes sociais, urbanistas e administradores interessados em políticas habitacionais para as camadas populares (Pierson, I942: I99). Em busca de recursos, Pierson se esforçou para que os anseios do estado e das elites econômicas por conhecimento aplicado convergissem com seu interesse no desenvolvimento das ciências sociais com base na investigação empírica sistemática. ${ }^{13}$

O Departamento de Administração do Serviço Público (DASP), criado durante o Estado Novo (Warlich, I983), também tinha expectativas quanto ao potencial prático da sociologia de Pierson tendo em vista a racionalização das esferas da administração e do trabalho e, em fins de i942, convidou o sociólogo para ministrar uma série de onze conferências no Rio de Janeiro. O curso do DASP faz parte das viagens que Pierson realizou para outras cidades, como Florianópolis e Belo Horizonte, e nos fornece uma pista sobre a circulação de suas ideias para além do Estado de São Paulo. ${ }^{\mathrm{I}} \mathrm{O}$ curso durou aproximadamente um mês, tendo dele participado Costa Pinto e Guerreiro Ramos, à época alunos de ciências sociais da Faculdade Nacional de Filosofia (FNFi). ${ }^{\text {I5 }}$ O programa de aulas foi dividido em duas seções, uma destinada à teoria e outra destinada à pesquisa, compreendendo os seguintes tópicos: as ciências sociais no mundo de hoje; o estudo da sociedade; associação; isolamento e contato; a cidade; métodos e técnicas nas ciências sociais; as inter-relações de teoria e pesquisa; desenvolvimento de uma atitude científica; o crescimento da cidade grande; o questionário e o formulário. ${ }^{16}$

Além de abordar aspectos epistemológicos e metodológicos da disciplina e discutir as normas da atividade científica, Pierson concebeu a cidade como importante cenário de estudos, na esteira de seu antigo professor Robert Park, para quem a metrópole de Chicago, considerada lócus de aceleradas mudanças sociais, serviu como um grande laboratório humano a céu aberto (Pier- 
son, I946b: 284). A ênfase de Pierson na pesquisa teve impacto sobre Costa Pinto e Guerreiro Ramos, que buscaram aliar a preocupação com a fundamentação científica da sociologia em bases empíricas com o interesse em colocá-la a serviço do processo de mudança social.

\section{UMA "FRENTE ÚNICA" DE ESPÍRITO CIENTÍFICO: Costa PINTO e A DEFESA MILITANTE dA PESQUisa SOCIOLÓgICA}

A recepção das concepções de Pierson no Rio de Janeiro transcorreu em um momento em que cientistas sociais em formação ou recém-egressos das primeiras turmas da FNFi buscavam alternativas para institucionalizar a atividade de pesquisa. A FNFi foi criada em I939 sob o estrito controle do Estado Novo e de setores conservadores ligados à Igreja Católica. Na conformação de seus quadros, a instituição absorveu alguns integrantes da extinta Universidade do Distrito Federal (UDF), ${ }^{17}$ como Arthur Ramos (Antropologia e Etnografia), além de contratar professores estrangeiros, como foi o caso dos franceses Jacques Lambert (Sociologia), Maurice Byé (Economia Política) e André Gross (Ciência Política) (Fávero, I989; Oliveira, I995a: 244-26I; Schwartzman et al., I 984: 2I4-2 I9). ${ }^{\text {I8 }}$ Em que pesem algumas iniciativas importantes, como a fundação da Sociedade Brasileira de Antropologia e Etnologia (SBAE) por Arthur Ramos, as Ciências Sociais na FNFi estiveram voltadas essencialmente para o ensino, não tendo logrado consolidar a atividade de pesquisa (Almeida, I989). Esta situação pode ser ilustrada pelo depoimento de Luiz de Aguiar Costa Pinto: “[...] a pesquisa era uma aspiração. Nunca houve pesquisa propriamente. $\mathrm{O}$ [Arthur] Ramos fazia alguma coisa, mas de uma maneira muito individual. Era dele, não era da faculdade" (Costa Pinto, I989: I4). ${ }^{\text {19 }}$

Em I942, após concluir o curso em ciências sociais, Costa Pinto foi nomeado assistente de Jacques Lambert na cadeira de Sociologia. Ao lado dos colegas Maurício Vinhas de Queiroz, Paulo Almeida Rodrigues e Zacarias de Sá Carvalho, ele havia criado na universidade o Centro de Estudos Sociais (CES). ${ }^{20}$ Em artigos publicados ao longo da década de i940, o sociólogo refletiu sobre a profissionalização e o ensino da disciplina, as dimensões teóricas e empíricas da pesquisa e os vínculos entre ciência e sociedade (Costa Pinto, I944a; I944b; I 949).

Costa Pinto manteve intensa correspondência com Donald Pierson na primeira metade dos anos I940, solicitando frequentemente ao sociólogo norte-americano críticas e sugestões bibliográficas para os programas de cursos que ministrava, além de livros e assinaturas de revistas científicas. Ele sugeriu que alunos da FNFi fizessem treinamento em pesquisa na ELSP com recursos da Fundação Rockefeller, ${ }^{21}$ instituição que vinha financiando Pierson em várias iniciativas, e vislumbrou ainda a possibilidade de realizar seu doutorado na Universidade de Chicago por sugestão do sociólogo norte-americano. ${ }^{22}$ 
Na FNFi, Costa Pinto explorou abordagens metodológicas e temas de pesquisa ligados à tradição de Chicago, ministrando cursos sobre Métodos e Técnicas de Pesquisa, Ecologia Humana e Patologia Social. ${ }^{23}$ As aulas de Ecologia Humana, consistindo em uma adaptação de curso realizado por Pierson na ELSP, previam "estudos práticos na cidade do Rio de Janeiro". ${ }^{24}$ Em I 945 , prestes a lecionar uma disciplina sobre Métodos de Pesquisas Sociológicas na Faculdade de Economia da Universidade do Brasil, Costa Pinto se queixa com Pierson da falta de "guias práticos" para "field workers" em ciências sociais e lamenta o fato de conduzir um curso de métodos "sem fazer nenhuma pesquisa sequer...". ${ }^{25}$

Costa Pinto se apresenta como fervoroso aliado de Pierson na defesa da sociologia como ciência fundada na investigação empírica sistemática e detentora de um universo conceitual próprio. Valendo-se de uma linguagem militante, ele afirma que a "batalha" pela rotinização dos padrões de trabalho científico passava pelo combate aos "sociólogos de gabinete":

Folgo [...] em que animou-se com saber o que se tem feito e como se tem lutado aqui [FNFi], embora com pouco sucesso, para vencer os "out-of-date armchair sociologists" e fazer alguma coisa de fato parecida com ciência social. Se o Snr. sentiu-se sozinho por longo tempo, creia que foi por não ter nos conhecido mais cedo, pois desde estudantes lá na $\mathrm{I}^{\mathrm{a}}$. série que trabalhamos neste sentido. Espero que de nossa troca de pontos de vista resulte de fato um trabalho conjunto, ombro a ombro, no sentido de criarmos um núcleo de estudos sérios de sociologia no Brasil. Desejo que isto seja tomado como um "pacto", uma verdadeira promessa no sentido de estarmos sempre colaborando e trocando ideias de modo que possamos sempre apresentar uma sólida "frente única" de espírito científico contra toda sorte de aventureirismo. ${ }^{26}$

Na perspectiva de Costa Pinto, a produção sociológica brasileira havia sido até então comprometida pelo "bacharelismo", espécie de precipitado ideológico da "superestrutura cultural de uma base econômica agrícola". A seu ver, a instauração da ordem social moderna no país correspondia, no domínio intelectual, à substituição do diletantismo pela atuação do sociólogo profissional envolvido em pesquisa. ${ }^{27}$

Ao propor uma reforma do ensino superior das ciências sociais em I944, Costa Pinto destaca a importância da formação de "técnicos nos vários setores das ciências sociais; [...] de pesquisadores e estudiosos da vida humana associativa e dos problemas sociais e econômicos do Brasil" (Costa Pinto, I944a: I9). Ele recomenda a criação tanto de cadeiras dedicadas exclusivamente à metodologia de pesquisa em sociologia e antropologia quanto de um Instituto de Pesquisas Sociais, com o nome de "Instituto de Relações Humanas", a exemplo do que se fazia nas universidades americanas. ${ }^{28} \mathrm{O}$ esforço de Costa Pinto em delimitar os objetos e domínios de conhecimento próprios à sociologia estavam afinados com o programa de ensino levado a cabo por Pierson na ELSP. Sua proposta curricular incluía matérias como Psicologia Social, Organização 
Social, Ecologia Humana, Desajustamentos Sociais, Sociologia Rural e Urbana, e Mudança Social. ${ }^{29}$

A preocupação com o desenvolvimento da pesquisa levou Costa Pinto, em meados dos anos I940, a considerar a possibilidade de realizar um estudo de comunidade. Com a promessa de conferir lastro empírico à análise da sociedade brasileira a partir da investigação in loco de diferentes aspectos da vida social, como o processo de mudança (Nogueira, I955), os estudos de comunidade vinham atraindo o interesse de cientistas sociais atuantes no país, datando deste período as incursões do antropólogo Emílio Willems e de Donald Pierson pelo interior do Estado de São Paulo que resultaram, respectivamente, nos trabalhos sobre Cunha e Cruz das Almas (Araçariguama). Costa Pinto imaginou uma investigação nestes moldes como parte de seu projeto de tese para concorrer à cátedra de Sociologia da FNFi, vaga com o retorno de Jacques Lambert à França ao final da guerra. Solicitando orientações a Pierson quanto aos "procedimentos de pesquisa", ele indica os temas de sua predileção:

\begin{abstract}
Embora fosse relativamente mais cômodo fazer um trabalho sobre métodos, como o que sugeriu sobre Park, preferiria fazer uma tese que fosse um Field Work, ou coisa parecida. Interessam-me particularmente problemas referentes aos seguintes assuntos: I) sociologia da família, 2) ecologia humana, 3) social change, 4) classes sociais. Pensei também numa pesquiza [sic] sobre uma típica comunidade rural brasileira, usando como método a observação participante. Acho que seria interessante estudar "a Brazilian Village", segundo os mesmos métodos de [Lloyd] Warner, [Robert] Redfield [...] e outros. Creio, entretanto, que um ótimo projeto exigiria um auxílio financeiro com que eu não conto. Acho [...] que um estudo sobre a família, no ambiente urbano do Rio de Janeiro, com um approach ecológico e analisando os aspectos de mudança e transformação da instituição - poderia dar assunto para um bom trabalho. ${ }^{30}$
\end{abstract}

Os interesses de Costa Pinto envolvendo família e mundo rural remontam ao estudo que realizou no início dos anos I 940 sobre os conflitos entre grupos familiares no período colonial brasileiro enfocando a prática da vingança privada enquanto forma de controle social. A lógica da vendeta, que mobilizava todos os membros de uma facção contra os de outra na punição de um delito, atestava a preponderância social do poder privado da grande família patriarcal sobre a autoridade pública (Costa Pinto, I949). Neste caso, Costa Pinto dialogava com autores do pensamento social brasileiro que abordaram as relações entre público e privado na formação social do país, a exemplo de Oliveira Vianna, Sérgio Buarque de Holanda e Nestor Duarte. O sociólogo chamava a atenção, contudo, para a tensão e a interdependência histórica daqueles domínios, buscando se afastar da visão disjuntiva que informava a análise de seus predecessores (Botelho, 2009).

Costa Pinto conjuga sua preocupação com estes e outros temas, como estratificação e mudança social, a enfoques consagrados nas pesquisas dos sociólogos de Chicago, como a ecologia humana. A abordagem ecológica foi 
valorizada na medida em que o estudo da distribuição diferenciada das classes e dos grupos étnicos no espaço urbano podia ser um indicativo de tensões e conflitos sociais (Costa Pinto, I947b: I83). ${ }^{\text {I }}$ Em sua proposta de pesquisa, o sociólogo faz ainda alusão a autores norte-americanos que constituíam importante referência para os estudos de comunidade, como Robert Redfield, antropólogo social de Chicago. Redfield coordenou uma série de pesquisas na Península de Iucatã a fim de avaliar o grau de mudança experimentada por diferentes localidades conforme seu maior ou menor contato com o mundo urbano moderno (Redfield, I949). Embora o projeto de Costa Pinto não tenha se concretizado, os diferentes temas e abordagens apontados pelo sociólogo como possíveis pontos de partida revelam sua agenda de pesquisa na FNFi.

\section{COSTA PINTO INTERPELA PIERSON: A CRÍTICA DA SOCIOLOGIA COMO IDEOLOGIA}

A estreita relação que Costa Pinto e Pierson estabeleceram não foi destituída de tensões. Costa Pinto presta com frequência reverências a Pierson, colocando-se como discípulo, ao mesmo tempo em que manifesta a vontade de ser reconhecido como par. Ao longo dos anos I 940 essas tensões se acentuam, revelando diferentes perspectivas em jogo acerca do afazer sociológico, do papel do cientista social e da relação com o mundo dos valores.

Em março de 1944, Pierson criticou Costa Pinto por sua defesa de uma tomada de posição dos sociólogos no contexto da guerra. Tendo por base o relatório da American Sociological Society sobre as relações entre o ensino da sociologia nos Estados Unidos e o conflito mundial, Costa Pinto havia ressaltado, em artigo no jornal Diário de Notícias, a necessidade de os professores da disciplina intervirem em um mundo marcado por convulsões sociais, difundindo os valores que inspiravam a "guerra antifascista" (Costa Pinto, I944b). Pierson enxergava nesta perspectiva o risco de os cientistas sociais se tornarem "meras servas e propagandistas de qualquer 'ismo' particular e limitado" e, em passagem de inspiração weberiana, adverte Costa Pinto de que a ciência jamais poderia determinar os fins morais e políticos a serem perseguidos pelos homens. ${ }^{32}$

Apesar dessas divergências, Costa Pinto permanece próximo à narrativa piersoniana acerca do florescimento científico da disciplina. Prova disto é sua conferência na FNFi em setembro de I944 sobre o legado intelectual de Robert Park. Ele afirma que os sociólogos norte-americanos, herdeiros das principais tradições intelectuais europeias, haviam conseguido superar as "polêmicas" entre "escolas, sistemas e correntes antagônicas", estabelecendo um corpus de conhecimento cuja validade era determinada pela experiência (Costa Pinto, I944C: 2-3). O desenvolvimento da sociologia se devia ao "espírito americano", valorizador do associativismo, do "trabalho coletivo" e do "pragmatismo" (Costa Pinto, I944C:3). ${ }^{33}$ 
É somente a partir de I 946 que as diferenças de perspectiva se acentuam a ponto de significarem uma guinada na visão de Costa Pinto sobre a objetividade e a unidade paradigmática da sociologia, principalmente em sua vertente norte-americana. Costa Pinto passa a denunciar o caráter ideológico da produção sociológica nos Estados Unidos, investindo na reflexão sobre as injunções sociais presentes na atividade científica. ${ }^{34}$ Reagindo à observação de Pierson de que muitos intelectuais e estudantes brasileiros de ciências sociais, ao buscarem verdades absolutas, confundiam ciência, religião e política, ${ }^{35}$ Costa Pinto assinala ironicamente, em carta de julho de I946, que a sociologia norte-americana não estava imune "à inspiração desta ou daquela ideologia (no sentido de Mannheim) [...] de que nem sempre o cientista tem consciência". ${ }^{36}$

A visão de Costa Pinto sobre as marcas ideológicas das ciências sociais norte-americanas foi apresentada de forma sistemática no artigo "Sociologia e mudança social", resultado de uma conferência feita pelo sociólogo em maio de 1947 na Sociedade Brasileira de Antropologia e Etnologia e publicado naquele mesmo ano na revista Sociologia. Neste texto, Costa Pinto defende uma sociologia comprometida com o processo de mudança social que funcionasse ao mesmo tempo como crítica da sociedade e instrumento de predição e direção dos seus rumos.

A argumentação de Costa Pinto se torna mais nítida se considerarmos a interlocução que estabelece com a visão piersoniana da sociologia. ${ }^{37}$ Mobilizando autores que pensaram as relações entre conhecimento e estrutura social, como Marx e Mannheim, além de conhecidos críticos da sociologia norte-americana, como Wright Mills e Robert Lynd (Villas Bôas, I999; Lima, I999; Brasil Jr., 20I3), Costa Pinto põe em xeque a cientificidade do que denomina sociologia acadêmica. Seus adeptos, ao apostarem em uma ciência axiologicamente neutra, acabavam abraçando, voluntária ou involuntariamente, uma ideologia ligada à justificação da ordem social dominante (Costa Pinto, I947a: 326). Os estudos de comunidade eram prova disto. O uso que faziam do conceito de comunidade encobria os conflitos de classe, identificando os diferentes segmentos da sociedade a um todo homogêneo do ponto de vista dos valores e dos interesses (Costa Pinto, I947a: 325)..$^{38}$

Realizando um "acerto de contas" com o ethos científico propugnado por Pierson, Costa Pinto afirma que, em vez de ser o produto de esforços voluntários de controle do viés do cientista ou de uma posição equidistante em relação aos valores, a objetividade em ciências sociais seria conquistada mediante a alteração das circunstâncias sociais que distorciam ideologicamente a pesquisa. Costa Pinto discorda da crença de Pierson em um crescente consenso cognitivo entre os sociólogos. Ele aponta para a persistência de impasses e divergências entre posições metodológicas no interior da disciplina que, por refletirem contradições e antagonismos presentes na própria sociedade, só podiam ser superados mediante a transformação desta (Costa Pinto, I947a: 
319). A seu ver, “o zelo em apresentar nossa ciência como já tendo atingido um estágio que deixava para o passado a fase de 'multiplicidade' de escolas" constituía apenas estratégia para impor determinada concepção de sociologia como única legítima (Costa Pinto, I947a: 318).

Em um contexto de aceleradas mudanças em curso, em que assumia primeiro plano o processo de desestruturação da ordem social dominante, uma postura objetiva diante dos fenômenos sociais, em vez de exigir imparcialidade ou neutralidade por parte do sociólogo, pressupunha o reconhecimento da nova ordem e dos novos valores que se desenvolviam no interior das antigas estruturas. ${ }^{39}$ Costa Pinto identifica na sociologia acadêmica uma força cultural a serviço das formas antigas de dominação em choque com formas emergentes, mais sintonizadas com o sentido da mudança social (Costa Pinto, I947a: 329).

Costa Pinto argumenta que a disciplina somente conseguiria superar sua feição ideológica colocando-se a favor da mudança e fazendo da ação critério central de validação do conhecimento: "só pela intervenção consciente no processo social, só pela prática e pela ação social, pode a teoria sociológica revelar e confirmar seu anseio de objetividade, tornando-se consciente de que pensar é uma forma de agir - e dando sentido a sua ação, para sincronizá-la com a própria mudança social" (Costa Pinto, I947a: 33I). A exortação de Marx à transformação do mundo para além de sua interpretação, presente nas famosas teses sobre Feuerbach, devia inspirar a atuação dos sociólogos.

O artigo de Costa Pinto suscitou as respostas de Emílio Willems e Florestan Fernandes, que fizeram comentários no mesmo número de Sociologia em que o texto foi publicado..$^{\circ}$ Marca de um contexto em que a autonomização do campo da sociologia era vista como tarefa premente, ambas as reações sublinham a importância do problema levantado por Costa Pinto, relativo ao condicionamento social do conhecimento, tendo em vista as possibilidades de conquista da objetividade em pesquisa (Willems, I947: 348; Fernandes, I947: 336). O uso científico da sociologia do conhecimento devia, contudo, sobrepor-se a seu uso político enquanto instrumento de denúncia das posições ideológicas assumidas pelos sociólogos. Buscando salvaguardar o status científico das ciências sociais, Emílio Willems e Florestan Fernandes recusam a identificação, sugerida por Costa Pinto (I947a: 322), entre sociologia e socialismo marxista, ainda que Fernandes estivesse mais disposto do que Willems a reconhecer a contribuição de Marx para o desenvolvimento da disciplina (Willems, I947: 349; Fernandes, I947: 343). Na medida em que sustentam a demarcação de fronteiras entre ciência e política, as críticas de Willems e Florestan convergem com a visão de Pierson sobre o fazer sociológico.

Pierson não torna pública sua posição relativamente ao debate em torno de "Sociologia e mudança social", e seu silêncio incomoda Costa Pinto, que registra ironicamente o fato em carta a Florestan Fernandes, de I948: 
Fico satisfeito de saber que meu artigo teve sucesso em São Paulo - entendendo-se por sucesso não o aplauso, mas o fato de ele ter obrigado outros a pensarem nesses problemas que lhes são sistematicamente ocultados no ensino acadêmico. E desconfio que os que mais pensaram foram aqueles que lhes fizeram críticas pela importância que deram ao trabalho... Que disse o Fernando de Azevedo? E o Donald Pierson? ${ }^{41}$

A tentativa de Costa Pinto de tomar conhecimento, por intermédio de Florestan, das reações de Pierson nos sugere um progressivo afastamento intelectual do primeiro em relação ao sociólogo norte-americano. Pierson, ao lado de Fernando de Azevedo, é considerado, ademais, como representante expressivo do contexto universitário paulista, ambiente que Costa Pinto passa a associar à sociologia acadêmica. Na mesma carta a Florestan, chamando a atenção para as mistificações ideológicas envolvendo a noção de cultura, à semelhança da crítica por ele endereçada ao conceito de comunidade, Costa Pinto afirma que a perspectiva marxista, segundo a qual a cultura devia ser estudada a partir de seus vinculações com a estrutura social, dificilmente encontraria acolhida na ELSP:

Note este detalhe: para um marxista isto é coisa evidente por si mesma, mas os acadêmicos fazem um tão ridículo conceito de cultura que nos obriga a fazer ênfase nesses aspectos. Neste falso conceito de cultura, que a concebe como alguma coisa pairando no ar, neste erro da mística acadêmica portanto, repousa 90\% do que chamam antropologia cultural que pretende estudar a cultura como uma realidade em si. Afirmei, certa feita que, na moderna sociologia, a cultura ocupa a mesma posição demiúrgica que a ideia na filosofia de Hegel. Que lhe parece? Imagino que num ambiente como o da Escola Livre, por exemplo, uma tal opinião herética soaria como uma voz do outro mundo... falando chinês! ${ }^{42}$

Em sua crítica à noção de cultura, Costa Pinto lança dúvidas sobre o poder explicativo da antropologia no estudo da vida social, contrapondo-se à tradição da ELSP que, principalmente a partir da atuação de Pierson, associou de modo estreito sociologia e antropologia, valorizando a pesquisa etnográfica.

Ao final dos anos I940, as discordâncias entre Donald Pierson e Costa Pinto tornam-se nítidas. Apoiadas em categorias como comunidade e cultura, as ciências sociais nos Estados Unidos e seus representantes acadêmicos no Brasil perdiam de vista, segundo Costa Pinto, a centralidade das relações sociais e dos conflitos que lhes eram constitutivos para a compreensão da vida humana, visão que o sociólogo vinha desenvolvendo desde sua pesquisa sobre as lutas de família no país (Villas Bôas, 2006b: I I I). As divergências também diziam respeito à própria concepção do trabalho científico. Enquanto Pierson imagina o desenvolvimento de uma sociologia aplicada a partir do progresso científico, Costa Pinto não opera com a divisão da ciência entre básica e aplicada, fazendo da aplicação elemento indispensável para o avanço do conhecimento sociológico. Em que pese o distanciamento gradativo de Costa Pinto em relação a Pierson, ligado a seu esforço de construir uma identidade sociopro- 
fissional para o sociólogo a meio caminho entre o cientista-pesquisador e o intelectual militante, a centralidade da pesquisa na transformação epistemológica da sociologia se mantém como horizonte comum.

\section{GUERREIRO RAMOS E A ESCOLA SOCIOLÓGICA DE CHICAGO}

Nos anos I940, a visão do sociólogo Alberto Guerreiro Ramos acerca do amadurecimento científico da sociologia como campo de conhecimento científico esteve marcada pelas lições de Donald Pierson. Sem perspectivas de inserção profissional na universidade ao término de sua graduação na FNFi, em I 943 o sociólogo enveredou pelos quadros da burocracia do Estado, desenvolvendo sua reflexão sociológica no DASP e no Departamento Nacional da Criança. Embora grande parte da literatura dedicada à produção intelectual de Guerreiro Ramos chame a atenção para sua postura crítica em relação aos cânones "importados" das ciências sociais nos anos I950 e I960 e acentue as controvérsias públicas em que se envolveu na defesa de uma ciência social autóctone (Oliveira, I995b; Werneck Vianna, I997; Villas Bôas, 2006b), no período em tela o sociólogo partilhou da perspectiva de consolidar uma sociologia científica mediante a investigação empírica, além de ter mantido intercâmbio intelectual com cientistas sociais e instituições universitárias em São Paulo.43 Em I949, a avaliação de Guerreiro da produção sociológica no Brasil, partindo de critérios institucionais, considerava a criação dos cursos superiores como marco do desenvolvimento da disciplina, conferindo destaque às atividades de Pierson na ELSP (Maio, I997).

A participação de Guerreiro Ramos nas aulas de Pierson no DASP, em novembro de I942, ocorre em um momento em que as ciências sociais vinham se tornando objeto de atenção crescente do sociólogo, até então mais interessado em estudos literários e filosóficos, principalmente os de fundo religioso (Azevêdo, 2006; Rios, I983).44 Por meio dos vínculos intelectuais que passou a desenvolver com Pierson neste momento, Guerreiro se aprofunda no estudo da literatura sociológica norte-americana. ${ }^{45} \mathrm{Em} \mathrm{I944,} \mathrm{a} \mathrm{possibilidade} \mathrm{de} \mathrm{fazer}$ uma pós-graduação nos Estados Unidos esteve no horizonte profissional do sociólogo, que pleiteou uma bolsa de estudos junto à Embaixada americana por intermédio de Arthur Ramos.

A afinidade de Guerreiro Ramos com a ciência sociológica de Pierson torna-se patente em suas aulas na cadeira de Problemas Econômicos e Sociais do Curso de Puericultura e Administração do Departamento Nacional da Criança (DNCr), órgão criado durante o Estado Novo tendo em vista a coordenação das políticas de saúde e assistência à infância em âmbito nacional. O curso visava à formação de médicos puericultores, incumbidos da orientação e fis calização dos serviços estaduais e municipais de proteção materno-infantil. No centro das políticas do DNCr estavam os problemas da mortalidade infan- 
til, do abandono de crianças e do menor infrator, objetos de um amplo leque de ações em assistência social, educação e saúde.

Guerreiro conferiu importância à pesquisa social na formação do puericultor, propondo uma cadeira dedicada exclusivamente à metodologia de pesquisa e destinando um terço das aulas de I 944 ao ensino de técnicas e métodos de investigação (Guerreiro Ramos, I944a). Em I945, empreendeu entrevistas diretas com famílias cujos filhos eram assistidos pelo Serviço de Obras Sociais, entidade filantrópica fundada por enfermeiras do Departamento Nacional de Saúde Pública. Empregou, na ocasião, a técnica da história de vida, recorrendo a cartas escritas pelos sujeitos da pesquisa, recurso consagrado desde o estudo de William Thomas e Florian Znaniecki sobre os imigrantes poloneses em Chicago (Guerreiro Ramos, I946b). Em I948, o sociólogo se inspirou na escala de distância social de Emory Bogardus ao aplicar questionários a uma turma de alunos do DASP com o objetivo de sondar atitudes raciais (Guerreiro Ramos, I948c).

No esforço de legitimar o conhecimento sociológico, Guerreiro Ramos afirma que a disciplina se desembaraçava de "sistemas filosóficos pessoais" (Guerreiro Ramos, I944a: I5). Estava ultrapassado o "período das escolas em que se acreditava na existência de uma sociologia francesa, de uma sociologia alemã e de uma sociologia norte-americana" (Guerreiro Ramos, I944a: I5). A fim de atestar a cientificidade da disciplina, Guerreiro lança mão de um expediente argumentativo marcadamente piersoniano, aproximando as ciências sociais das ciências físicas: "Assim como não há uma física de Einstein ou de Dirac, uma física inglesa ou alemã, mas a física simplesmente, do mesmo modo, não há uma sociologia de Durkheim, uma sociologia de Burgess, mas uma sociologia 'tout court', cujos conceitos são válidos universalmente" (Guerreiro Ramos, I944a: I6). Neste período, também à semelhança de Pierson, ele associa a objetividade científica à busca pela superação do bias de pesquisa (Guerreiro Ramos, I948a). A sociologia não era "uma tagarelice de homens ociosos", mas produto da prática de profissionais treinados.

Guerreiro Ramos buscou construir uma sociologia dos problemas da infância no Brasil capaz de subsidiar as políticas sociais do DNCr. Referências constantes do sociólogo a The Polish peasant in Europe and America, de Thomas e Znaniecki, ao compêndio Introduction to the science of sociology, de Roberto Park e Ernest Burgess e The city, livro organizado por ambos, além dos estudos de Clifford Shaw e Henry Mckay sobre a delinquência juvenil nos guetos e slums, sugerem que Chicago constituía importante recurso legitimador da perspectiva sociológica que procurou desenvolver (Guerreiro Ramos, I944a; 1948b).

Na visão de Guerreiro Ramos, a mortalidade infantil e a delinquência juvenil se concentravam em zonas urbanas de desorganização social, categoria central a partir da qual os problemas ligados ao crime, à prostituição e à delinquência infantil foram interpretados pelos sociólogos de Chicago (Chapou- 
lie, 200I). A identificação destes espaços devia orientar a "organização das vizinhanças" e das "comunidades desorganizadas" como formas de intervenção social de caráter preventivo. Tratava-se de promover a reestruturação de ambientes como "cortiços, pardieiros, vielas onde a população se adensa em espaços insuficientes", e também das favelas, mediante políticas públicas de puericultura, alimentação e habitação. Atento às indicações de Pierson quanto aos recursos metodológicos a serem empregados no estudo da cidade, Guerreiro Ramos sugeriu, na esteira dos estudos de Ernest Burgess, o mapeamento ecológico da cidade do Rio de Janeiro, capaz de lançar luzes sobre a distribuição espacial dos problemas sociais (Guerreiro Ramos, I944a: 4I).46

A sociologia também era instrumental para ações mais individualizadas, de caráter terapêutico, sobre o comportamento desviante. Tendo como referência os trabalhos de Lawrence Guy (Social pathology) e de Clifford Shaw (The natural history of a delinquent career), Guerreiro sugeriu uma "clínica sociológica" visando à reeducação dos jovens "desajustados". Empregando a técnica da história de vida, o médico podia reunir informações sobre a vida cotidiana de seus pacientes por meio de cartas, diários e depoimentos de amigos e familiares. As escolas também podiam aplicar "escalas sociométricas" a fim de sondar atitudes e verificar desvios potenciais (Guerreiro Ramos, I944b: 325). Guerreiro tinha em mente, neste caso, a tentativa do sociólogo Lowell Juilliard Carr, do Michigan Child Guidance Institute, de aferir a probabilidade de que crianças "mal-ajustadas" ao ambiente social norte-americano ingressassem no crime (Carr, I94I).

\section{TENSIONANDO A SOCIOLOGIA DE PIERSON:} CIÊNCIA COMO INSTRUMENTO DE AÇÃO

A ênfase que Guerreiro Ramos confere ao caráter prático das ciências sociais é o que mais diferencia sua perspectiva em relação a Pierson neste período, fornecendo pistas sobre a leitura que operou da sociologia norte-americana. Com efeito, enquanto Pierson se aproxima com cautela do problema da aplicabilidade, Guerreiro afirma ser possível divisá-la no presente, definido como "etapa da história em que é possível o domínio consciente da sociedade e do comportamento individual" (Guerreiro Ramos, I 944b: 324). A seu ver, o "homem moderno [estava] se emancipando das forças sociais, como já se emancipou das forças do mundo físico" (Guerreiro Ramos, I946b: II).

O destaque atribuído à aplicabilidade se fez acompanhar do esforço de Guerreiro em expandir o espaço de atuação dos sociólogos profissionais, apontando funções técnicas que estes podiam desempenhar no âmbito do Estado, mediante o desenvolvimento de pesquisas diretamente relacionadas aos problemas sociais do país. Era preciso instituir o "cientista social de carreira nos quadros do serviço público" (Guerreiro Ramos, I945:3). No caso do DNCr, a 
criação de escalas sociométricas convenientes à criança brasileira exigia o trabalho conjunto de médicos, psicólogos, sociólogos, psicólogos sociais treinados em pesquisa. Em suas palavras:

\begin{abstract}
Temos mais de dez Faculdades de Filosofia com cursos de ciências sociais. A oportunidade que o Departamento Nacional da Criança [...] abre àqueles que se dedicam às ciências sociais é a de tomar contato com os fenômenos de que tratam suas disciplinas não através de livros, mas de fato. Assim poderíamos descolonializar [sic] os nossos processos de pesquisa social concernentes à criança, descobrindo técnicas próprias e contribuindo para criar no país um ambiente científico genuíno no terreno das ciências sociais, ligado ao problema da criança, ambiente onde passassem a ser ridículas as atitudes livrescas e as inoperantes demonstrações de erudição, vício tão comum numa certa casta de pseudocientistas que nada fazem senão importar teorias alheias para embasbacar o indígena desprevenido e de boa fé... (Guerreiro Ramos, I944b: 326).
\end{abstract}

A ideia de que o Estado podia constituir espaço privilegiado para o desenvolvimento científico no Brasil esteve ancorada em uma visão negativa sobre o ensino das ciências sociais no país. Segundo Guerreiro, nas universidades predominava uma formação intelectual "livresca, demasiadamente teórica e abstrata", desligada da realidade social brasileira e dos desafios que esta colocava (Guerreiro Ramos, I 945:3). Guerreiro elogiava, todavia, o padrão de ensino da ELSP, afirmando que as Faculdades de Filosofia precisavam incorporar novas disciplinas no currículo das ciências sociais, como Sociologia Rural, Psicologia Social, Antropologia Social, Patologia Social, História Social e Econômica do Brasil, além de promover cursos monográficos de sociologia e economia (Guerreiro Ramos, I 945:3). Órgãos públicos como o DNCr, estabelecendo laços de cooperação com as instituições acadêmicas, podiam oferecer farto material de estudo e pesquisa aos graduandos em ciências sociais, pondo-os em contato com os problemas sociais do país.

$\mathrm{Na}$ crítica ao ensino da sociologia em nível superior, Guerreiro levou em consideração sua experiência na FNFi, afirmando que "na capital do Brasil, os raros especialistas em assuntos sociológicos [estavam] trabalhando em condições muito precárias, quase estritamente às custas de sobras de tempo [...]" (Guerreiro Ramos, I947b:I24). Esta visão é ratificada em seu balanço sobre os estudos sociológicos no país, publicado em I949. Guerreiro indica que havia apenas alguns esforços individuais e isolados de pesquisa nos diferentes estados brasileiros, dentre os quais se incluíam, além daquele empreendido por ele mesmo, as iniciativas de Arthur Ramos, Gilberto Freyre, Thales de Azevedo, Edison Carneiro e Luiz de Aguiar Costa Pinto (Guerreiro Ramos \& Garcia, I949: Io).

Nesse quadro, São Paulo constituía exceção pelo "pioneirismo" da ELSP no treinamento de estudantes em pesquisa (Guerreiro Ramos \& Garcia, I949: 9) e na condução do trabalho em equipe. Pierson representava o modelo de cientista social versado em métodos e técnicas de investigação e capaz de perscrutar os diferentes aspectos sociais e culturais do país. O saber-fazer da pesquisa 
empírica que vinha divulgando devia ser valorizado enquanto movimento de exploração da realidade social brasileira. A metodologia sociológica norte-americana constituía, nas palavras de Guerreiro, um "instrumental eficaz da pesquisa não só na América do Norte, como no Brasil" (Guerreiro Ramos \& Garcia, I949: I6). Nas ocasiões em que se refere ao trabalho de Pierson na ELSP, Guerreiro faz uma leitura que ressalta o potencial prático do seu empreendimento, como o aproveitamento, em instituições públicas e privadas paulistas, de técnicos treinados em pesquisa aptos a trabalhar na área de políticas sociais (Guerreiro Ramos, I945: 3; Guerreiro Ramos \& Garcia, I949: Io), em contraste com a forma como o próprio Pierson compreendia seus objetivos principais na instituição, ligados à consolidação da sociologia com base na investigação empírica.

Diante da falta de perspectivas quanto à institucionalização da pesquisa, Guerreiro sugeriu que a constituição do campo da sociologia se efetivasse mediante estreita associação com agências governamentais, na interface com suas respectivas agendas de políticas públicas. A seu ver, o Estado e as classes dirigentes demandavam cada vez mais a atuação de especialistas e técnicos com formação sociológica no enfrentamento dos desafios postos pela sociedade. Em artigo intitulado sugestivamente "Novos rumos das ciências sociais na América Latina" (I947b), ao notar a multiplicação na região de "instituições, privadas e públicas, de amparo às atividades científicas de especialistas em ciências sociais", o sociólogo afirma:

A complexidade da etapa histórica em que vivemos exige a intervenção crescente das ciências sociais no governo da sociedade. Este governo [...] se torna, de modo crescente, função das tecnologias sociais, ou seja, da boa aplicação das ciências sociais. [...] embora o status das ciências sociais ainda esteja assinalado por certa marginalidade, já se observa que nos grupos dominantes está amadurecendo a consciência da necessidade de aplicação sistemática destas disciplinas no tratamento dos problemas (Guerreiro Ramos, I947b: I22).

A proposta de ordenação da prática científica contida neste texto evidencia o movimento que Guerreiro Ramos vinha operando no sentido da redefinição das fronteiras da disciplina, tal como Pierson a compreendia, e que implicava a ênfase em sua dimensão aplicada:

A ocasião é favorável [...] àqueles que se dedicam ao estudo [das] ciências [sociais]. Afigura-se-nos que o melhor meio de aproveitar esta oportunidade é a elaboração de trabalhos rigorosamente técnicos sobre problemas atuais. Para atingir este objetivo, deveriam colaborar, de um lado, as instituições que dispõem de recursos destinados à promoção do progresso científico e, de outro lado, os especialistas. Estes últimos, entretanto, de maneira organizada, pois um dos obstáculos mais ponderáveis para o desenvolvimento de qualquer ciência é o individualismo profissional. Não pode haver progresso científico, seja em que campo for, sem institutos de pesquisas, sem o debate objetivo e bem intencionado, sem o intercâmbio cultural. Onde não existem estas condições, o trabalho científico se torna difícil, e raramente são aproveitadas cabalmente as energias dos que a ele se dedicam [...] (Guerreiro Ramos, I947b: I22). 
Guerreiro não enxergou como excludentes a atuação de cientistas sociais em "institutos de pesquisas", a promoção do "debate objetivo e bem intencionado" e a "elaboração de trabalhos rigorosamente técnicos sobre problemas atuais". Propôs, neste sentido, a institucionalização da prática das ciências sociais a partir da confluência entre as demandas da sociedade brasileira e as investigações sociológicas, que resultaria, inclusive, em benefício destas últimas. A aplicabilidade se impunha também como forma de legitimação social dos sociólogos. Superando as "tendências acadêmicas", estes deviam realizar trabalhos "cuja utilidade, como instrumentos de ação, seja indiscutível" (Guerreiro Ramos \& Garcia, I949: I2).

Assim como Pierson, Guerreiro Ramos afirma que o desenvolvimento da disciplina havia sido impulsionado por questões de ordem prática, ligadas ao enfrentamento de problemas sociais. Contudo, esta visão parecia justificar, a seu ver, a defesa da associação estreita, no presente, entre ciência social calcada na pesquisa, de um lado, e os processos de formulação de políticas governamentais, do outro. Procurando dar conta das especificidades dos problemas sociais do país, como aqueles ligados ao bem-estar infantil, os sociólogos ultrapassariam sua fase pré-científica, atuando como grupo capaz de prover bases científicas à atuação das classes dirigentes (Guerreiro Ramos, I947b: I 22).

No período em exame, a prática da sociologia como intervenção social não foi vista por Guerreiro Ramos como implicando a adesão a valores políticos. A aplicação foi defendida como uma forma de equacionamento técnico neutro em relação aos problemas sociais, equidistante dos posicionamentos político-ideológicos em choque na sociedade. Em entrevista ao jornal A Manhã intitulada "Uma opinião: mais sociologia e menos política", Guerreiro Ramos observa que a "planificação deve constituir uma técnica neutra, cuja discussão será sociológica e não ideológica” (Guerreiro Ramos, I945: 3). Em um período de crescente pressão pelo fim do Estado Novo e pela redemocratização do país, o sociólogo afirma que a democracia não era "somente uma questão de debate político, uma questão de princípios", mas, sobretudo, uma questão de engenharia social: "Ela consiste em transformar o Estado num autêntico servidor do homem comum" (Guerreiro Ramos, I945: 6). Tratava-se de aprofundar a intervenção governamental em matéria de políticas sociais que se iniciara no Governo Vargas. Em resenhas bibliográficas para a Revista do Serviço Público, veículo difusor das ideias do DASP, em que a reflexão de Guerreiro se volta para os temas da administração, da racionalidade técnica e da burocracia tendo em vista as possibilidades de modernização da sociedade brasileira (Bariani, 20 I I), o sociólogo reforça este ponto de vista, destacando a necessidade de "intervir na organização social [...] sociologicamente" (Guerreiro Ramos, I946a: I66).

Assim como Pierson, Guerreiro Ramos acreditou na possibilidade de produzir conhecimento sociológico à distância do mundo da política. Todavia, a afirmação da neutralidade científica serviu, em seu caso, para endossar a 
perspectiva mannheimiana de que os sociólogos, assumindo as tarefas da planejamento do Estado, se convertessem em uma intelligentsia apta a diagnosticar as necessidades da sociedade em seu conjunto.

Guerreiro Ramos também estava de acordo com a crença piersoniana de que o empreendimento sociológico moderno tendia a assumir contornos transnacionais, classificando, por vezes, a produção em ciências sociais em termos de "tradições" ou "tendências" nacionais (Guerreiro Ramos, I947a; I948a). No entanto, o problema da universalidade do conhecimento sociológico somente será objeto de sua reflexão sistemática a partir da década de I950, com a publicação de O processo da sociologia no Brasil (I953). Neste livro, gestado em uma nova fase de sua atuação intelectual e política, em que a temática do desenvolvimento emerge com força, o sociólogo argumenta em favor da criação de uma ciência social autóctone como ferramenta de "autodeterminação da sociedade nacional" (Guerreiro Ramos, I953: 9).47 Afirmando que os rumos da atividade científica eram invariavelmente determinados por contingências sociais e históricas, a exemplo dos contextos nacionais específicos em que seus praticantes se inseriam, Guerreiro Ramos problematiza o ideal de universalidade defendido pelos sociólogos..$^{48}$ No mesmo movimento, abandona o critério institucional na avaliação do desenvolvimento da produção sociológica no país, investindo no diálogo com autores da tradição de pensamento social brasileiro como Silvio Romero, Euclides da Cunha, Alberto Torres e Oliveira Vianna.

\section{CONSIDERAÇÕES FINAIS}

A delimitação das fronteiras da "Ciência da Sociologia" foi um dos objetivos perseguidos por Donald Pierson ao se estabelecer no Brasil. Ele se preocupou em definir a atividade do sociólogo profissional em termos de investigação empírica. O conhecimento sociológico devia ser estabelecido intramuros acadêmicos, conforme regras intrínsecas à comunidade de especialistas, autorizados pelo treino e tempo de dedicação ao campo. Era preciso estabelecer uma linguagem conceitual comum, para além de barreiras nacionais de qualquer ordem, bem como substituir as antigas controvérsias filosóficas pelo confronto sistemático das ideias com o mundo empírico, única forma de conferir consenso epistêmico e unidade paradigmática à nova ciência.

Pierson esposava uma concepção de ciência que previa a aplicabilidade, compartilhando com seus pares da Universidade de Chicago a crença na utilidade do conhecimento sociológico para a ação reformadora (Chapoulie, 200I: I52). No entanto, em face do desenvolvimento incipiente da sociologia relativamente às ciências do mundo físico, a aplicabilidade foi vista como limitada e modesta no presente. No contexto brasileiro, esta situação se agravava, tendo em vista o atraso do país em relação aos progressos feitos pelas ciências 
sociais nos Estados Unidos. Em todo caso, para Pierson, a manipulação bem-sucedida dos processos sociais se colocava mais no plano das expectativas, de modo que prescrições práticas deveriam ser feitas com reserva pelos sociólogos. Embora a instituição da pesquisa sociológica estivesse ligada historicamente à demanda pela solução de problemas sociais, a investigação devia ser conduzida à distância dos interesses de aplicação imediata.

Nas perspectivas de Costa Pinto e Guerreiro Ramos, a sociologia veiculada por Pierson atestava as credencias científicas que as ciências sociais em sua feição moderna e norte-americana vinham conquistando e que justificavam a necessidade de profissionalização, no Brasil, do ofício do sociólogo e do técnico especializado nos problemas sociais, juntamente com a institucionalização da prática de pesquisa. Sob este prisma, as interpretações sobre o país que não se apoiavam no conjunto de métodos e técnicas identificados à investigação empírica passaram a ser compreendidas na chave do autodidatismo e do diletantismo.

Ao se apropriarem das ideias de Pierson, Costa Pinto e Guerreiro Ramos buscaram, no entanto, alargar o escopo de atuação dos sociólogos, indicando outros papéis sociais que poderiam exercer na sociedade brasileira para além do homem de ciência e do sociólogo-pesquisador. A aproximação de Costa Pinto com as concepções de Pierson revelou gradativamente tensões entre ambos, ligadas principalmente às expectativas do primeiro em relação a uma maior intervenção do cientista social no debate público como intelectual difusor de valores e concepções de mundo. A atuação do sociólogo como cientista devia incorporar a função de crítico da sociedade e da cultura, influindo sobre seus rumos. Costa Pinto defende um horizonte normativo para a pesquisa e a teorização sociológicas associado a ideais de transformação social.

Por seu turno, Guerreiro Ramos tensionou as fronteiras da visão científica da sociologia proposta por Pierson na direção de um projeto mais ambicioso de intervenção social. Nos anos I940, esta redefinição de fronteiras disciplinares não significou uma oposição radical entre as ciências sociais orientadas pela investigação empírica, nos moldes imaginados por Pierson, e o desenvolvimento de uma sociologia aplicada que ele próprio buscou fomentar a partir de sua atuação no DNCr e no DASP, uma sociologia a serviço de programas de engenharia social, ligada ao planejamento governamental e à implementação de políticas públicas. Tomando para si muitos dos parâmetros da sociologia norte-americana para a produção de conhecimento, Guerreiro afirmou que seus objetos de estudo deviam ser construídos com base na agenda política nacional.

A recepção das concepções de Donald Pierson acerca da sociologia por parte de Costa Pinto e Guerreiro Ramos implicou um movimento de aproximação, apropriação e afastamento dos ideais de ciência e de cientista defendidos pelo sociólogo norte-americano em que se evidencia uma linha de continui- 
dade com a tradição de pensamento social preocupada em interpretar e ao mesmo tempo influir sobre os rumos da sociedade brasileira. Para tais autores, ao ingressar no mundo das ciências, profissionalizando-se, os sociólogos não podiam perder de vista os desafios postos pela modernização do país, assumindo, ao lado das tarefas de especialistas envolvidos em pesquisa, a função social mais ampla de intelectuais comprometidos com a esfera pública.

Recebido em 22/I2/20I4 | Aprovado em 30/03/2015

Marcos Chor Maio é doutor em Ciência Política pelo Instituto Universitário de Pesquisas do Rio de Janeiro (IUPERJ), pesquisador titular da Casa de Oswaldo Cruz/Fiocruz, professor do Programa de Pós-Graduação em História das Ciências e da Saúde (PPGHCS/COC/Fiocruz). É autor de Nem Rotschild, nem Trotsky: o pensamento anti-semita de Gustavo Barroso (I992), e coeditor de diversas coletâneas, entre as quais, Raça como questão: História, ciência e identidades no Brasil (2010).

Thiago da Costa Lopes é doutorando do Programa de Pós-Graduação em História das Ciências e da Saúde (PPGHCS/COC/Fiocruz). 


\section{NOTAS}

*Agradecemos aos pareceristas anônimos pelos valiosos comentários, críticas e sugestões.

I A expressão, que revela o esforço de Pierson em marcar a identidade profissional dos cientistas sociais é recorrente em sua correspondência. Ver Carta de Pierson a Luiz de Aguiar Costa Pinto, I9/4/I944, 4p. Darcy Ribeiro se valeu do mesmo lema para firmar seu compromisso com o projeto de Pierson. Carta de Darcy Ribeiro a Oracy Nogueira, 8/I I/I943. 2p. Fundo Donald Pierson/Arquivo Edgard Leuenroth/UNICAMP (FDP/AEL/UNICAMP) Ao lado de Oracy Nogueira, Luiz de Aguiar Costa Pinto, dentre outros, Darcy integrou o "círculo de correspondência" estabelecido por Pierson em 1943.

2 A importância de Pierson na formação de Oracy Nogueira, Florestan Fernandes, Darcy Ribeiro e Virgínia Leone Bicudo foi abordada por diferentes autores. Ver Cavalcanti (I999), Arruda (I995), Bomeny (200I) e Maio (2010; 20I4).

3 Os inquéritos sobre o padrão de vida do operariado paulista realizados por Horace Davis e Samuel Lowrie nos anos I930 ilustram os fins práticos que a instituição manteve em seu horizonte (Del Vecchio \& Diéguez, 2008).

4 Carta de Pierson a Luiz de Aguiar Costa Pinto, 2/8/I943. FDP/AEL/UNICAMP, 4p.

5 Carta de Pierson a Luiz de Aguiar Costa Pinto, 3/7/1943. FDP/AEL/UNICAMP, 3 p.

6 Carta de Pierson a Luiz de Aguiar Costa Pinto, I I/6/ı 943. FDP/AEL/UNICAMP, Ip.

7 Carta de Pierson a Luiz de Aguiar Costa Pinto, 2/8/1943. FDP/AEL/UNICAMP, $4 \mathrm{p}$.

8 A série de conferências realizadas por Pierson em Belo Horizonte em setembro de I943, a convite dos estudantes da Universidade Federal de Minas Gerais, parecia confirmar suas expectativas em relação ao crescente "interesse genuíno [no Brasil] nas ciências sociais, especialmente entre os moços e as moças. A velha superficialidade e o lero lero nesses assuntos parecem estar gradativamente dando lugar a preocupações mais fundamentais". Carta de Pierson ao secretário de relações culturais da Embaixada 
Americana Joseph Piazza,ı3/9/ı943. FDP/AEL/UNICAMP, ıp. Tradução livre. A expressão "lero lero" é de Pierson.

9 Carta de Pierson a Luiz de Aguiar Costa Pinto, 2/8/1943. FDP/AEL/UNICAMP, 4p.

Io Pierson se aproximava de uma concepção pragmatista de conhecimento esposada por sociólogos de Chicago, como William Thomas, para quem a aplicabilidade constituía importante critério de validação do saber científico (Wegner, I993). O padrão de ciência propugnado por Pierson é abordado em Oliveira (I995a), Limongi (I989) e Lopes (20I2). Sua proposta de delimitação do campo sociológico é cotejada com a perspectiva de Gilberto Freyre por Meucci (2006), que analisa os manuais introdutórios à sociologia que esses autores publicaram nos anos I940.

I I Sobre a guinada da perspectiva de Pierson em relação à aplicabilidade da sociologia e ao envolvimento do sociólogo na intervenção social, ver Maio et al. (2013).

I 2 Dentre os responsáveis pela fundação do IDORT encontram-se alguns dos principais mantenedores da ELSP, como Antonio Carlos Pacheco e Silva, Raul Briquet, André Dreyfuss e Roberto Simonsen (ver Limongi, I989). Durante o governo do interventor paulista Armando Salles de Oliveira, o IDORT foi elevado à condição de órgão de utilidade pública. Ver Weinstein (2000).

I3 Em depoimento sobre suas atividades no Brasil, Pierson chama a atenção para o problema da escassez de verbas na ELSP (Pierson, I987: 93). Ele também assinala o auxílio financeiro que entidades norte-americanas, como a Fundação Rockefeller, prestaram às suas iniciativas de pesquisa na cidade de São Paulo no início dos anos 1940 (Pierson, I987: IOI).

I4 Por ocasião das conferências proferidas em Belo Horizonte em I943, Pierson travou contato com estudantes da Universidade Federal de Minas Gerais como Darcy Ribeiro, que acabou se tornando seu aluno na ELSP (Pierson, I987: 6I).

I5 O curso de Pierson não representou, todavia, o primeiro contato com a sociologia norte-americana por parte dos estudantes da FNFi. Obras como An outline of the principles of sociology, organizada por Robert Park, vinham sendo consultadas tanto por Costa Pinto quanto por Guerreiro 
Ramos desde meados de I942. Em maio de I942, nas aulas de sociologia de Jacques Lambert, Costa Pinto apresentara palestra sobre o pensamento de Lester Ward, considerado um dos fundadores da sociologia nos Estados Unidos ("Diários de classe". Arquivo FNFi/PROEDES/UFRJ). No mesmo ano, o sociólogo da Universidade da Pensilvânia, William Rex Crawford, havia proferido, na qualidade de adido cultural da Embaixada americana, uma conferência na FNFi sobre a "Sociologia norte-americana” (Araújo, I956). Também Gilberto Freyre, nos anos I930, contribuiu para a veiculação das ciências sociais produzidas nos Estados Unidos a partir dos cursos que ministrou na Universidade do Distrito Federal. O livro-texto de Park e Burgess, Introduction to the science of sociology, constituiu, no plano conceitual, uma das principais referências de suas aulas (Meucci, 2006: I46).

I6 “Conferências fora de São Paulo". FDP/AEL/UNICAMP.

I7 Vindo à luz em I935, em um período de polarização ideológica no cenário político nacional, a UDF foi marcada pela instabilidade administrativa e pela ingerência do Governo Federal em seus quadros, fechando as portas em I939. Tem-se indicado, no entanto, o caráter inovador da instituição, cuja criação se inseria em um amplo projeto de modernização do ensino público da capital federal a cargo de Anísio Teixeira (Schwartzman et al., I984; Barbosa, I996).

I8 Ferreira (2012) analisou as formas, baseadas em redes de relações, de recrutamento de professores que lecionaram na FNFi neste período, enfocando a estruturação do curso de História e Geografia. Parte do conteúdo das aulas de Lambert, Byé e Gros foi abordada em Lopes (2012).

I9 Oliveira (I995a) chama a atenção, contudo, para outras iniciativas e instituições no Rio de Janeiro que viabilizaram o desenvolvimento da pesquisa em ciências sociais em anos posteriores, como o Centro Brasileiro de Pesquisas Educacionais e o Centro Latino-Americano de Pesquisas em Ciências Sociais.

20 Juntamente com a SBAE, o CES organizou uma conferência de Pierson em I 942 sobre as bases metodológicas de sua pesquisa enfocando as relações raciais na Bahia (Pierson, I945C: 44I).

2 I Carta de Costa Pinto a Pierson, 3/4/i943. FDP/AEL/UNICAMP, Ip.

22 O assunto ocupa espaço considerável na correspondência entre ambos. Após longas negociações para a obtenção da bolsa, 
Costa Pinto teve o visto negado pelo governo norte-americano em função de seus vínculos com o Partido Comunista Brasileiro. Carta de Costa Pinto a Pierson, 30/5/1946, incluinco cópia de carta de Costa Pinto endereçada ao Ministro das Relações Exteriores, João Neves da Fontoura, FDP/AEL/UNICAMP, 3p. Por recomendação de Pierson, Costa Pinto seria orientado por Everett Hughes. Carta de Pierson a Costa Pinto, I I/2/I946. FDP/AEL/UNICAMP, 3p.

23 Carta de Costa Pinto a Pierson, I8/4/I946. FDP/AEL/UNICAMP, Ip.

24 Carta de Costa Pinto a Pierson, I8/3/I944. FDP/AEL/UNICAMP, Ip.

25 Carta de Costa Pinto a Pierson, 6/4/I945. FDP/AEL/UNICAMP, Ip.

26 Carta de Costa Pinto a Pierson, 8/8/1943. FDP/AEL/UNICAMP, $2 \mathrm{p}$.

27 Carta de Costa Pinto a Pierson, 8/8/I943. FDP/AEL/UNICAMP, $2 \mathrm{p}$.

28 Carta de Costa Pinto a Pierson, 29/I/I944, , incluindo seu anteprojeto de reforma do ensino superior de ciências sociais. FDP/AEL/UNICAMP, 8p.

29 Carta de Costa Pinto a Pierson, 29/I/I944, incluindo seu anteprojeto de reforma do ensino superior de ciências sociais. FDP/AEL/UNICAMP, 8p. Na perspectiva de Pierson, os problemas científicos da sociologia podiam ser divididos em três ramos principais de investigação: "Organização Social" ("como é possível aos seres humanos realizarem atos coletivos [...] ação conjugada"); "Mudança Social" ("processos pelos quais surgem novas formas de associação humana") e "Psicologia Social" ("os resultados da associação humana sobre os indivíduos") (Pierson, I945a: 49-50).

30 Carta de Costa Pinto a Pierson, I5/8/I945. FDP/AEL/UNICAMP, $2 p$

3I Em I942, Costa Pinto apresentou estudo sobre a distribuição espacial das classes sociais na Bahia do século XVII na SBAE. Diário de Notícias. Primeira Seção. "Associações Culturais e Científicas". Rio de Janeiro, 9/5/ı942, p. 6.

32 Carta de Pierson a Costa Pinto, 23/3/I944. FDP/AEL/UNICAMP, 2p. Tradução livre. 
33 Trata-se de texto-chave para compreender o modo como Costa Pinto operou a leitura de conceitos e abordagens oriundos de Chicago, a exemplo da Ecologia Humana. Ao enfocar as "bases naturais" das relações sociais e da cultura, isto é, as "relações simbióticas", inconscientes e involuntárias, dos homens entre si e com seu ambiente visando ao "fim imediato da subsistência e da sobrevivência", a Ecologia Humana conferia novo impulso à "dialética materialista", à compreensão das relações entre infra e superestrutura ou entre a produção da vida material e o "nível sociocultural", que Park denominara "ordem moral" (Costa Pinto, I944c: 8-9).

$34 \mathrm{O}$ interesse de Costa Pinto em explorar as relações entre ciência e sociedade é visível nas assinaturas de revistas americanas feitas por intermédio de Pierson, a exemplo de Science and Society. Por ocasião deste pedido em particular, Pierson observa que o enfoque da revista incidia "menos na ciência do que na doutrina marxista", ao que Costa Pinto se limita a agradecer pela informação. Carta de Pierson a Costa Pinto, 5/6/I946. FDP/AEL/UNICAMP, 2p. Tradução livre.

35 Carta de Pierson a Costa Pinto, 29/6/I946. FDP/AEL/UNICAMP, Ip.

36 Carta de Costa Pinto a Pierson, 3/7/I946. FDP/AEL/UNICAMP, Ip. Também neste período, em resenha sobre artigo de William Ogburn, Costa Pinto observa que "grande parte da bibliografia sociológica que os Estados Unidos exportam para o mundo" estaria viciada com "acentuado 'American way" por uma "visão curta” (I946: 227).

37 Pierson é referido, em nota, no início do artigo como um dos sociólogos então preocupados com o problema da objetividade (Costa Pinto, I947: 289).

38 Wright Mills, um dos autores mobilizados por Costa Pinto na crítica à sociologia acadêmica, havia chamado a atenção para a visão de sociedade subjacente aos manuais de patologia social correntes nos Departamentos de Sociologia dos Estados Unidos, observando que noções como as de "ordem social" e "organização social" pressupunham uma totalidade socialmente homogênea e harmônica (Mills, I943: I72). Esses textos geralmente abordavam os problemas sociais de forma fragmentária, sendo incapazes de correlacioná-los a estruturas sociais mais amplas (Mills, I943: I68). Dentre os autores que foram alvo da crítica de Mills encontram-se importantes referências para a tradição de pesquisas de Chicago, como Charles Cooley, 
Robert Park e Ernest Burgess. Sobre as críticas aos estudos de comunidade no Brasil, ver Consorte (I996), Jackson (2009) e Oliveira \& Maio (20I I).

39 Não é outro o significado de uma carta em que, ainda na expectativa de viajar a Chicago, Costa Pinto demonstra forte interesse pelos estudos de Obgurn sobre mudança social: "Considero a mudança o mais importante traço da vida social e sempre julgo os autores pela capacidade que revelam de entender a sociedade e a cultura como realidades em permanente transformação. [...] Esse prisma dialético que encara a sociedade como realidade em permanente mudança me parece o mais científico a que as ciências sociais podem atingir". Carta de Costa Pinto a Pierson, I 9/2/ı 946. FDP/AEL/UNICAMP, 2p.

40 As reações de Willems e Florestan também foram analisadas por Villas Bôas (I999).

4I Carta de Costa Pinto a Florestan Fernandes, 27/3/I948. UFSCar/Fundo Florestan Fernandes, 2p.

42 Carta de Costa Pinto a Florestan Fernandes, 27/3/I948. UFSCar/Fundo Florestan Fernandes, 2p. Grifos no original.

43 Analisando a recepção da obra de Guerreiro Ramos em diferentes períodos, Maia (2012: 277) observa que a leitura recorrente de sua sociologia a partir das chaves do nacionalismo e da contenda acabou consolidando a reputação do sociólogo enquanto "outsider" do mundo acadêmico, visão, todavia, que não resiste ao exame de sua produção intelectual nos anos I940.

44 É o que se depreende da relação de obras e autores que Guerreiro consultou na Biblioteca da FNFi no período I940I943. A partir de 1942, textos de Platão, Goethe, Nietzsche, e de escritores franceses como Proust, Jean Cocteau, Mallarmé e Brémond passam a dividir espaço com trabalhos de cientistas sociais como Arthur Ramos, Karl Mannheim, Maurice Halbwachs, Pitirim Sorokin e Wilhelm Dilthey. Desde meados de I942, Guerreiro vinha consultando obras sociológicas norte-americanas, como "An outline of the principles of sociology", de Park; "Social thought: from Lore to science", de H. Barnes e H. P. Becker, e "Principles of sociology”, de Edward Ross. Ver Catálogo Topográfico-Biblioteca. Arquivo FNFi/PROEDES/UFRJ. 
45 Parte considerável da literatura norte-americana utilizada por Guerreiro em seus cursos no DNCr e no DASP foi conseguida por intermédio de Pierson, a exemplo de: Folkways (Summer); Sociology (Ogburn \& Nimkoff); Social survey and research (Young); Social psychology (L. G. Brown); Social organization (Cooley); The urban community (Burgess); The natural history of a delinquent career (Shaw); The Jack Roller (Shaw); e Juvenile delinquency and urban areas (Shaw \& Mckay). Carta de Pierson a Costa Pinto, 27/4/I945. FDP/AEL/ UNICAMP, 2p.

46 Abranches (2005) analisa, no quinto capítulo de sua tese, os desdobramentos do enfoque ecológico da sociologia de Chicago no pensamento de Guerreiro Ramos sobre a nação nos anos I950.

47 Maio \& Lopes (20I2) abordam as mudanças na reflexão sociológica de Guerreiro sobre saúde pública no país neste período e seus vínculos com a questão do desenvolvimento.

48 Guerreiro ironiza a crença de que a universalidade do conhecimento seria garantida pela criação de uma comunidade científica transnacional, elemento importante na argumentação de Pierson: "Dir-se-á que a emergência de uma sociedade mundial supranacional está possibilitando à sociologia a superação das contingências regionais. Mas ainda que isto fosse verdade, (está muito longe disto), ainda que se atingisse a unidade cultural do gênero humano, através da 'unificação' das ciências e das categorias de toda a vida interior do homem, subsistiria a contingência mesma da espécie, limitando a perspectiva do conhecimento. É certo que se os anjos se convertessem à sociologia [...] sua universalidade estaria garantida, mas é discutível que eles se distraiam das suas fruições cognitivas para cometimento tão mesquinho, dentro de suas motivações" (Guerreiro Ramos, I953: 8). 


\section{REFERÊNCIAS BIBLIOGRÁFICAS}

Abranches, Aparecida Maria. (2006). Nacionalismo e democracia no pensamento de Guerreiro Ramos. Dissertação de Doutorado. Instituto Universitário de Pesquisas do Rio de Janeiro. Almeida, Maria Hermínia Tavares de. (I989). Dilemas da institucionalização das ciências sociais no Rio de Janeiro. In: Miceli, Sergio (org.), História das Ciências Sociais no Brasil. São Paulo: Idesp/Sumaré/Fapesp, p.r88-216 (vol. I).

Araújo, Milton. (I957). Relatório das atividades da Divisão de Ensino, durante o ano de I956. Arquivo FNFi/ PROEDES/ UFRJ, Pasta 2 I 8.

Arruda, Maria Arminda do Nascimento. (I995). A sociologia no Brasil: Florestan Fernandes e a "escola paulista". In: Miceli, Sergio (org.), História das Ciências Sociais no Brasil. São Paulo: Idesp/Sumaré/Fapesp, p.107-232 (vol. 2).

Azevêdo, Ariston. (2006). A sociologia antropocêntrica de Alberto Guerreiro Ramos. Dissertação de Doutorado. Universidade Federal de Santa Catarina.

Barbosa, Rosangela. (I996). O projeto da UDF e a formação de intelectuais na década de 30. Dissertação de Mestrado. PPGSA/Universidade Federal do Rio de Janeiro.

Bariano, Edison. (20I I). Guerreiro Ramos e a redenção sociológica. Capitalismo e sociologia no Brasil. São Paulo: Ed. UNESP. Bomeny, Helena. (200I). Darcy Ribeiro: sociologia de um indisciplinado. Belo Horizonte: Ed. UFMG.

Botelho, André. (2010). Passado e futuro das interpretações do país. Tempo Social, XXII/ı, p.47-66.

Botelho, André. (2009). Passagens para o Estado-nação: a tese de Costa Pinto. Lua Nova, 77, p.I47-I77.

Bourdieu, Pierre. (2002). Les conditions sociales de la circulation internationale des idées. Actes de la Recherche en Sciences Sociales, I45, p. 3-8.

Brasil Jr., Antonio. (2013), A reinvenção da sociologia da modernização: Luiz Costa Pinto e Florestan Fernandes (I950-I970). Trabalho, Educação e Saúde, I I/I, p. 229-249.

Bulmer, Martin. (1984). The Chicago School of Sociology - institutionalization, diversity, and the rise of sociological research. Chicago: The University of Chicago Press. 
Carr, Lowell J. (I94I). Delinquency control. Londres/Nova Iorque: Harpers \& Brothers.

Cavalcanti, Maria Laura V. de C. (I999). "O aspecto humano de nossos dados": a relação Pierson/Nogueira, a etnografia e a abordagem das relações raciais. In: Maio, Marcos C. \& Villas Bôas, Glaucia (orgs.). Ideias de modernidade e sociologia no Brasil: Ensaios sobre Luiz de Aguiar Costa Pinto. Porto Alegre: Ed. UFRGS, p.185-202.

Chapoulie, Jean M. (200I). La tradition sociologique de Chicago (I892-I96I). Paris: Éditions du Seuil.

Consorte, Josildeth Gomes. (I996). Os estudos de comunidade no Brasil: uma viagem no tempo. In: Faleiros, Maria Izabel \& Crespo, Regina Aida (orgs.), Humanismo e compromisso: Ensaios sobre Octavio Ianni. São Paulo: Ed. Unesp, p. 5 I-68.

Corrêa, Mariza. (I995). A antropologia no Brasil (I960-I980). In: Miceli, Sergio (org.), História das ciências sociais no Brasil. São Paulo: Idesp/Sumaré/Fapesp, p. 25-106 (vol. 2).

Costa Pinto, Luiz de Aguiar. (1989). Depoimento a Lucia Lippi Oliveira, Maria Stella Amorim e Alzira Alves Abreu. Rio de Janeiro, mimeo.

Costa Pinto, Luiz de Aguiar. (I949). Lutas de família no Brasil. São Paulo: Companhia Editora Nacional (Coleção Brasiliana).

Costa Pinto, Luiz de Aguiar. (I947a). Sociologia e mudança social. Sociologia: Revista Didática e Científica, IX/4, p. 287-33 I.

Costa Pinto, Luiz de Aguiar. (I947b). Mário Filho - O negro no foot-ball brasileiro. Resenha bibliográfica. Sociologia: Revista Didática e Científica, IX/2, p.I8I-I84.

Costa Pinto, Luiz de Aguiar. (I946). William F. Ogburn - Sociology and the atom". Resenha bibliográfica. Sociologia: Revista Didática e Científica, VIII/3, p. 227-230.

Costa Pinto, Luiz de Aguiar. (1944a). O ensino das ciências sociais no Brasil: sugestões para uma reforma. Sociologia: Revista Didática e Científica, VI/I, p. I5-22.

Costa Pinto, Luiz de Aguiar. (I944b). Tendências recentes do ensino das ciências sociais: Sociologia. Diário de Notícias, Rio de Janeiro, I9 mar., p. 2.

Costa Pinto, Luiz de Aguiar. (I944C). A contribuição de Park à sociologia moderna. Mensário do Jornal do Commercio, ano I I 8/25 (Tomo XXVIII). 
Coulon, Alain. (I995). A Escola de Chicago. São Paulo: Papirus.

Del Vecchio, Angelo \& Diéguez, Carla (orgs.). (2008). As pesquisas sobre o padrão de vida dos trabalhadores da cidade de São Paulo: Horace Davis e Samuel Lowrie, pioneiros da sociologia aplicada no Brasil. São Paulo: Editora Sociologia e Política.

Fávero, Maria de Lourdes de A. (I989). Faculdade Nacional de Filosofia: Projeto ou trama universitária? Rio de Janeiro: Ed. UFRJ (vol. I).

Fernandes, Florestan. (I947). O problema do método na investigação sociológica. Sociologia: Revista Didática e Científica, IX/4, p. 332-345.

Ferreira, Marieta de Moraes. (2012). O ensino da história na Faculdade Nacional de Filosofia da Universidade do Brasil. História, Ciências, Saúde - Manguinhos, XIX/2, p. 6I I-636.

Guerreiro Ramos, Alberto. (I 949). Problemas econômicos e sociais do Brasil. Rio de Janeiro: Departamento Nacional da Criança.

Guerreiro Ramos, Alberto. (I948a). Cursos de administração, divisão de seleção e aperfeiçoamento. DASP, mimeo.

Guerreiro Ramos, Alberto. (I948b). W. I. Thomas (I863I947). Revista do Serviço Público, Rio de Janeiro, II/I-2, p. I59-160.

Guerreiro Ramos, Alberto. (I948c). Imigração e preconceito. A Manhã, Rio de Janeiro, 4 jul., p. 2.

Guerreiro Ramos, Alberto. (I947a). A hipótese da demora cultural. Revista do Serviço Público, I/I-2, p. I52-4.

Guerreiro Ramos, Alberto. (I947b). Novos rumos das ciências sociais na América Latina. Revista do Serviço Público, IV/I, p. I 22-I 24.

Guerreiro Ramos, Alberto. (I946a). Notas sobre planificação social. Revista do Serviço Público, IV/3, p. I63-I68.

Guerreiro Ramos, Alberto. (1946b). Um inquérito sobre quinhentos menores. Rio de Janeiro: Imprensa Nacional.

Guerreiro Ramos, Alberto. (I945). Uma opinião: mais sociologia e menos política. A Manhã, Rio de Janeiro, I7 jun., p. 3-6. Guerreiro Ramos, Alberto. (I944a). Aspectos sociológicos da puericultura. Rio de Janeiro: Imprensa Nacional. 
Guerreiro Ramos, Alberto. (I944b). Uma concepção multidimensional da criança. Jornal de Pediatria, Rio de Janeiro, jul., p. 314-326.

Guerreiro Ramos, Alberto \& Garcia, Evaldo da Silva. (1949). Notícia sobre as pesquisas e os estudos sociológicos no Brasil (I940-I 949). Rio de Janeiro: Conselho de Imigração e Colonização.

Grynnzpan, Mario. (20I2). Por uma sociologia histórica da circulação e da recepção de textos: Robert Michels e Sociologia dos Partidos Políticos nos Estados Unidos. Revista de Sociologia e Política, XX/44, p. I I-30.

Jackson, Luiz Carlos. (2009). Divergências teóricas, divergências políticas: a crítica da USP aos "estudos de comunidades". Cadernos de Campo, I8, p. 273-280.

Lepenies, Wolf. (I996). As três culturas. São Paulo: Ed. USP. Lima, Nísia Trindade. (I999). Sob o signo de Augusto Comte ou sob o signo de Karl Marx: a vocação das ciências sociais nas perspectivas de Costa Pinto e Florestan Fernandes. In: Maio, Marcos Chor \& Villas Bôas, Glaucia (orgs.). Ideias de modernidade e sociologia no Brasil: Ensaios sobre Luiz de Aguiar Costa Pinto. Porto Alegre: Ed. UFRGS, p. 25 I-274. Limongi, Fernando. (1989). A Escola Livre de Sociologia e Política. In: Miceli, Sergio (org.). História das ciências sociais no Brasil. São Paulo: Sumaré/ Fapesp, p. 2 17-233 (vol. I).

Lopes, Thiago da Costa. (2012). Sociologia e puericultura no pensamento de Guerreiro Ramos: Diálogos com a Escola de Chicago (I 943-I948). Dissertação de Mestrado. PPGHCS/Casa de Oswaldo Cruz/Fiocruz.

Maia, João Marcelo. (20I 2), Reputações à brasileira: o caso de Guerreiro Ramos. Sociologia \& Antropologia, 2/4, p. 265-294. Maio, Marcos Chor. (20I4). O contraponto paulista: os estudos de Florestan Fernandes e Oracy Nogueira no Projeto Unesco de Relações Raciais. Antíteses, 7/I3, p. I0-39.

Maio, Marcos Chor. (2010). Educação sanitária, estudos de atitudes raciais e psicanálise na trajetória de Virgínia Leone Bicudo. Cadernos Pagu, 35, p. 309-355.

Maio, Marcos Chor. (1997). Uma polêmica esquecida: Costa Pinto, Guerreiro Ramos e o tema das relações raciais. DADOS - Revista de Ciências Sociais , 40/I, p. I27-I62. 
Maio, Marcos Chor; Oliveira, Nemuel da Silva \& Lopes, Thiago da Costa. (2013). Donald Pierson e o Projeto do Vale do Rio São Francisco: cientistas sociais em ação na era do desenvolvimento. DADOS - Revista de Ciências Sociais, 56/2, p. $245-284$.

Maio, Marcos Chor \& Lopes, Thiago da Costa. (2012). Da Escola de Chicago ao nacional-desenvolvimentismo: Saúde e nação no pensamento de Alberto Guerreiro Ramos (I940I950). Sociologias, I4/30, p. 290-329.

Meucci, Simone. (2006). Gilberto Freyre e a sociologia no Brasil: da sistematização à constituição do campo científico. Tese de Doutorado. Universidade Estadual de Campinas.

Nogueira, Oracy. (1955). Os estudos de comunidade no Brasil. Revista de Antropologia, III/2, p. 95-I03.

Oliveira, Lúcia Lippi. (I995a). As ciências sociais no Rio de Janeiro. In: Miceli, Sergio (org.), História das Ciências Sociais no Brasil. São Paulo: Idesp/Sumaré/Fapesp, p. 233-308 (vol. 2). Oliveira, Lúcia Lippi. (I 995b). A sociologia do Guerreiro. Rio de Janeiro: Ed. UFRJ.

Oliveira, Nemuel da Silva \& Maio, Marcos Chor. (20I I). Estudos de comunidade e ciências sociais no Brasil. Sociedade \& Estado, 26/3, p. 52 I-550.

Pierson, Donald. (1987). Depoimento. In: Corrêa, Mariza (org.). História da antropologia no Brasil: I930-I960. Testemunhos: Emílio Willems e Donald Pierson. São Paulo: Vértice/ Revista dos Tribunais/UEC, p. 29-I I6.

Pierson, Donald. (I946a). É ciência a sociologia?. Sociologia: Revista Didática e Científica, VIII/2, p. 88-IO2.

Pierson, Donald. (I946b). Robert E. Park: Sociólogo pesquisador. Sociologia: Revista Didática e Científica, VI/4, p. 282-294. Pierson, Donald. (I945a). Teoria e pesquisa em sociologia. São Paulo: Edições Melhoramentos.

Pierson, Donald. (I945b). Survey of the literature on Brazil of sociological significance published up to I940. Cambridge, MA: Harvard University Press/The Joint Committee on Latin American Studies.

Pierson, Donald. (I945C). Brancos e pretos na Bahia: estudo de contacto racial. São Paulo: Companhia Editora Nacional. Coleção Brasiliana. 
Pierson, Donald. (I942). Habitações de São Paulo: estudo comparativo. Revista do Arquivo Municipal, LXXXI, p. I99-238. Redfield, Robert. (I949). Civilização e cultura de folk: estudo de variações culturais em Yucatan. São Paulo: Martins Fontes. Rios, José Arthur. (1983). Quarto Painel - A teoria da delimitação dos sistemas sociais. Simpósio Guerreiro Ramos: resgatando uma obra. Revista de Administração Pública, I 7/2, p. I 20-I 23 .

Sá, Dominichi Miranda de. (2006). A ciência como profissão: médicos, bacharéis e cientistas no Brasil (I895-I935). Rio de Janeiro: Ed.Fiocruz.

Schwartzman, Simon; Bomeny, Helena Maria Bousquet \& Costa, Vanda Maria Ribeiro. (I984). Tempos de Capanema. Rio de Janeiro/São Paulo: Paz e Terra/Edusp.

Valladares, Licia do Prado. (20I0). A visita de Robert Park ao Brasil, o "homem marginal" e a Bahia como laboratório. Caderno CRH, XXIII/58, p. 35-49.

Valladares, Licia do Prado (org.). (2005). A Escola de Chicago - Impacto de uma tradição no Brasil e na França. Belo Horizonte/Rio de Janeiro: Ed. UFMG/IUPERJ.

Vila Nova, Sebastião. (I998). Donald Pierson e a Escola de Chicago na sociologia brasileira: Entre humanistas e messiânicos. Lisboa: Coleção Vega Universidade.

Villas Bôas, Glaucia. (2006a). A recepção da sociologia alemã no Brasil. Rio de Janeiro: Topbooks.

Villas Bôas, Glaucia. (2006b). Mudança provocada: passado e futuro no pensamento sociológico brasileiro. Rio de Janeiro: Ed. FGV.

Villas Bôas, Glaucia. (I999). Passado arcaico, futuro moderno: a contribuição de L. A. Costa Pinto à sociologia das mudanças sociais. In: Maio, Marcos Chor \& Villas Bôas, Glaucia (orgs.). Ideias de modernidade e sociologia no Brasil: Ensaios sobre Luiz de Aguiar Costa Pinto. Porto Alegre: Ed. UFRGS, p. 5I-60.

Warlich, Beatriz. (1983). Reforma administrativa na Era Vargas. Rio de Janeiro: Ed. FGV.

Wegner, Robert. (1993). Teoria sociológica na Escola de Chicago: a obra de William Isaac Thomas. Dissertação de Mestrado. Instituto Universitário de Pesquisas do Rio de Janeiro. 
Weinstein, Barbara. (2000). (Re)formação da classe trabalhadora no Brasil, I920-I964. São Paulo: Cortez/CPDAH/IFAN/ Universidade São Francisco.

Werneck Vianna, Luiz. (I 997). A revolução passiva: Iberismo e americanismo no Brasil. Rio de Janeiro: Revan.

Willems, Emílio. (I947). Sociologia "acadêmica" e sociologia "socialista". Sociologia: Revista Didática e Científica, IX/4, p. 346-349.

Wright Mills, Charles. (I943). The professional ideology of social pathologists. The American Journal of Sociology, $\mathrm{XLIX/2,} \mathrm{p.} \mathrm{I65-I80}$ 


\section{DONALD PIESON E AS CIÊNCIAS SOCIAIS NO RIO DE JANEIRO (1942-1949): "FOR THE ESTABLISHMENT OF THE SOCIAL DISCIPLINES AS SCIENCES"}

\section{Resumo}

Analisamos a recepção das concepções de sociologia propostas por Donald Pierson no Rio de Janeiro a partir dos casos de Luiz de Aguiar Costa Pinto e Alberto Guerreiro Ramos. Por meio de artigos, livros, conferências e aulas ministradas na Escola Livre de Sociologia e Política de São Paulo, Pierson se tornou um dos principais veiculadores, no Brasil, dos padrões de trabalho sociológico gestados na Universidade de Chicago. Recém-egressos do curso de Ciências Sociais da Faculdade Nacional de Filosofia, Costa Pinto e Guerreiro Ramos travaram contato com Pierson quando buscavam consolidar suas carreiras. Embora convergindo com os interesses de Pierson relativos à profissionalização do ofício de sociólogo e à consolidação da prática de pesquisa, ambos reinterpretaram sua "ciência sociológica", fundada no ideal do distanciamento do cientista em relação à esfera da ação prático-política, em um sentido mais ambicioso de intervenção social.

\section{DONALD PIERSON AND THE SOCIAL SCIENCES IN RIO DE JANEIRO (1942-1949): “FOR THE ESTABLISHMENT OF THE SOCIAL DISCIPLINES AS SCIENCES"}

The authors analyze the reception of Donald Pierson's conceptions of sociology in Rio de Janeiro, Brazil, based on the cases of Luiz de Aguiar Costa Pinto e Alberto Guerreiro Ramos. Pierson is known for having propagated certain patterns of scientific work associated with the Chicago School of Sociology through articles, books, lectures at Escola Livre de Sociologia e Política in São Paulo and conferences throughout the country. Costa Pinto e Guerreiro Ramos, former students in Social Sciences at Faculdade Nacional de Filosofia, approached Pierson's ideas while struggling to consolidate their career as sociologists. Despite agreeing with Pierson on the importance of establishing a professional identity and of promoting research-based inquiries, they reinterpreted some aspects of his "science of sociology", replacing the ideal of noncommitment to political and practical action with a more ambitious agenda of social intervention.

\section{Palavras-chave}

Donald Pierson;

História das Ciências Sociais no Rio de Janeiro;

Luiz de Aguiar Costa Pinto;

Escola Sociológica

de Chicago;

Alberto Guerreiro Ramos.

\section{Keywords}

Donald Pierson;

History of Social Sciences in Rio de Janeiro;

Luiz de Aguiar Costa Pinto; Chicago School of Sociology; Alberto Guerreiro Ramos. 